\title{
NASA Glenn Icing Research Tunnel: 2012 Cloud Calibration Procedure and Results
}

\author{
Judith F. Van Zante ${ }^{1}$, Robert F. Ide ${ }^{2}$ and Laura E. Steen ${ }^{3}$ \\ Sierra Lobo, Inc., Cleveland, OH, 44135
}

\begin{abstract}
In 2011, NASA Glenn's Icing Research Tunnel underwent a major modification to it's refrigeration plant and heat exchanger. This paper presents the results of the subsequent full cloud calibration. Details of the calibration procedure and results are presented herein. The steps include developing a nozzle transfer map, establishing a uniform cloud, conducting a drop sizing calibration and finally a liquid water content calibration. The goal of the calibration is to develop a uniform cloud, and to build a transfer map from the inputs of air speed, spray bar atomizing air pressure and water pressure to the output of median volumetric droplet diameter and liquid water content.
\end{abstract}

\section{Nomenclature}

$\begin{array}{ll}\text { CDP } & =\text { Cloud Droplet Probe, droplet sizer, } 2-50 \mathrm{um} \\ \text { CIP } & =\text { Cloud Imaging Probe, droplet sizer, } 15-930 \mathrm{um} \\ \text { DeltaP } & =\text { Pwat }- \text { Pair (psid) } \\ \text { FSSP } & =\text { Forward Scattering Spectometer Probe }- \text { droplet sizer, } 2-47 \mathrm{um} \\ \text { FZDZ } & =\text { Freezing Drizzle } \\ \text { FZRA } & =\text { Freezing Rain } \\ \text { LWC } & =\text { Liquid Water Content }\left(\mathrm{g} / \mathrm{m}^{3}\right) \\ \text { MVD } & =\text { Median Volumetric Diameter }(\mu \mathrm{m}) \\ \text { OAP-230X } & =\text { Optical Array Probe, droplet sizer, } 15-450 \mathrm{um} \\ \text { OAP-230Y } & =\text { Optical Array Probe, droplet sizer, } 50-1500 \mathrm{um} \\ \text { Pair } & =\text { Spray nozzle atomizing air pressure }(\mathrm{psig}) \\ \text { PDI } & =\text { Phase Doppler Interferometer, droplet sizer, } 4-200 \mathrm{um} \\ \text { PIP } & =\text { Precipitation Imaging Probe, droplet sizer, } 100-6200 \mathrm{um} \\ \text { Pwat } & =\text { Spray nozzle water pressure (psig) } \\ \text { SLD } & =\text { Supercooled large droplets } \\ \text { TWC } & =\text { Total Water Content }\left(\mathrm{g} / \mathrm{m}^{3}\right) \\ \text { um } & =\text { micron }\end{array}$

\section{Introduction}

$\mathrm{N}_{\mathrm{i}}^{\mathrm{s}} \mathrm{se}$ ASA GLENN'S Icing Research Tunnel, or IRT, has undergone a significant upgrade with the replacement of its original refrigeration plant and change to the heat exchanger. The icing cloud calibration effort that took place from November 2011 to January 2012 is reported here. The cloud calibration follows SAE ARP-5905 "Calibration and Acceptance of Icing Wind Tunnels ${ }^{1}$." Steps include optimizing the cloud uniformity in the test section, a drop size calibration and liquid water content calibration. Companion papers detail the aero-thermal calibration of the test section by Pastor-Barsi ${ }^{2}$, the aero-thermal calibration in the plenum area to investigate the effects of the new heat exchanger by Steen ${ }^{3}$ and a numerical model of the IRT with the new and old heat exchangers by Clark ${ }^{4}$.

${ }^{1}$ AeroMechanical Engineer, Facilities and Test Division, NASA Glenn Research Center, and AIAA Senior Member.

${ }^{2}$ AeroMechanical Engineer, Facilities and Test Division, NASA Glenn Research Center.

${ }^{3}$ AeroMechanical Engineer, Facilities and Test Division, NASA Glenn Research Center, and AIAA Member. 


\section{IRT Refrigeration Plant and Heat Exchanger Replacement}

In 2010, NASA Glenn Research Center received approval for the expenditure of American Recovery and Reinvestment Act (ARRA) stimulus funds for improvements to the Icing Research Tunnel. Both the original 1940s refrigeration plant and the 1999 flat panel heat exchanger were to be upgraded. NASA Glenn had three objectives for the upgrade:

(1) Reduce the static temperature from $-27 \mathrm{C}$ to $-40 \mathrm{C}$.

(2) Increase operational efficiencies.

(3) Reduce or eliminate ice particle shedding from the heat exchanger.

The design-build contract was awarded to Jacobs Engineering, Co. (Tullahoma, TN). Figure 1a is their schematic depicting the cooling loops in the refrigeration plant (lower right) and the heat exchanger (upper left). They proposed and built a secondary heat transfer fluid system. The coolant fluid remains in the refrigeration plant building. The secondary fluid circulates from there through the heat exchanger. Jacobs also recommended a staggered panel - instead of the flat panel - heat exchanger as a way to minimize the pressure drop and thereby the ice crystal shedding risk. IRT Facility and Icing Branch personnel agreed to compromise some degree of aerodynamic quality to help ensure no or minimum ice crystal shedding. The heat exchanger design schematic is shown in Figure 1b.

Subsequent testing has shown that the objectives were largely met. The IRT can hold -43 C static temperature. The operational efficiency has improved greatly. This includes both reduced maintanence and operational costs, as well as time required to get on condition and stabilize during testing. The temperature uniformity in D-Corner has also improved significantly and is very stable. It will be shown later that the ice crystal shedding from the heat exchanger is vastly improved and possibly eliminated, with with an increase in the maximum speed in the test section.

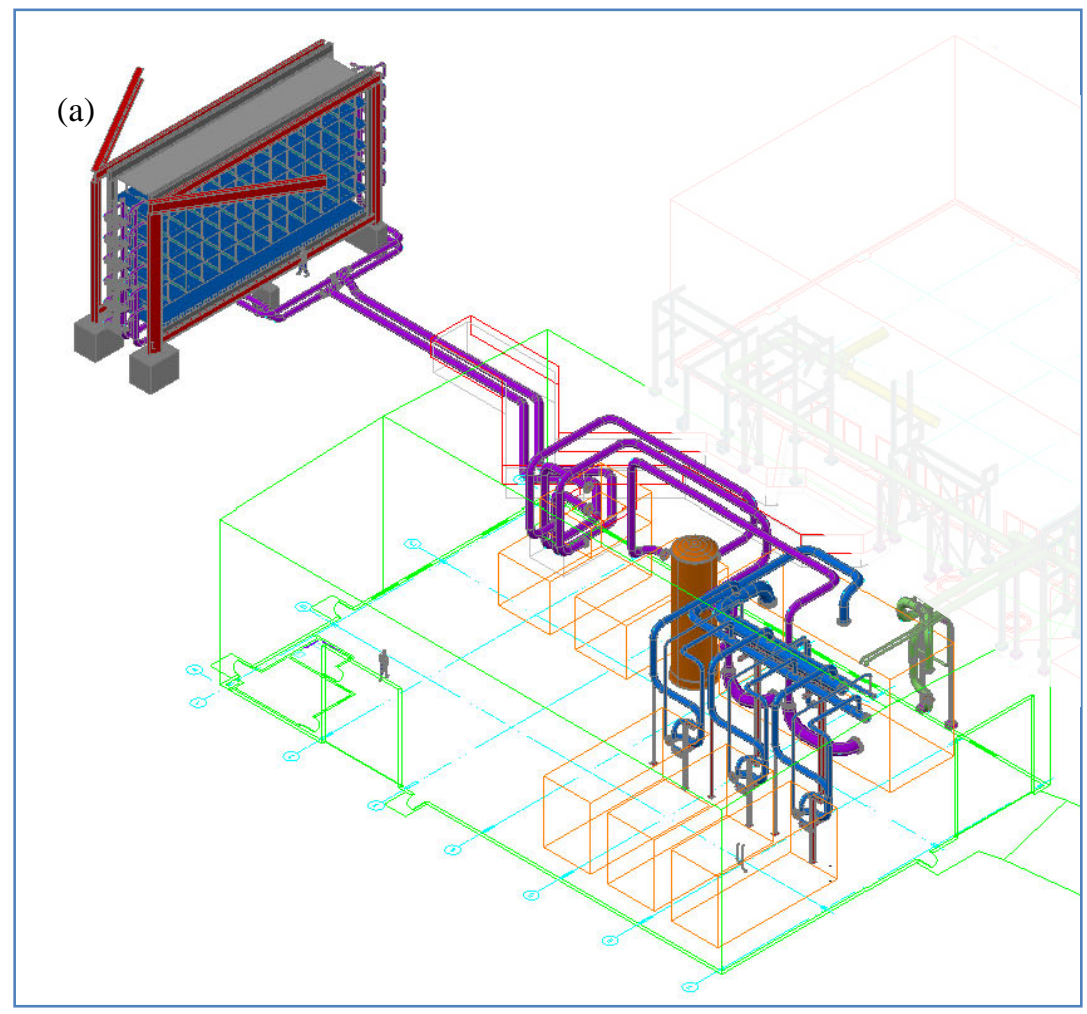

(b)

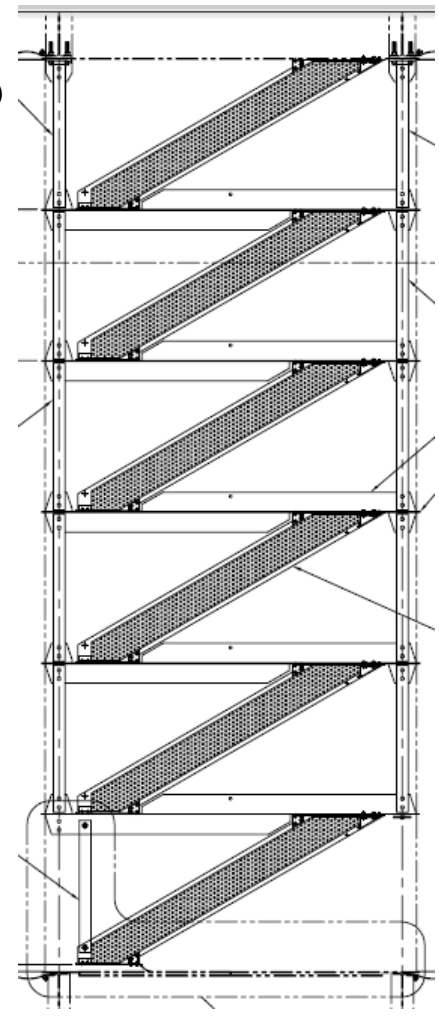

Figure 1. Schematic of IRT's new heat exchanger and refrigeration plant: (a) new refrigeration plant with heat exchanger. Schematics courtesy of Jacobs Engineering; (b) side view of staggered heat exchanger (flow is right to left). 


\section{Tunnel Description}

The IRT is a closed-loop refrigerated wind tunnel that simulates flight through an icing cloud. A plan view of the facility is shown in Figure 2. A 5000-hp electric motor drives the 24-ft fan made of wood from Sitka spruce. The calibrated speed range in the test section is from 50 to 350 knots (kts).

The fan drives air through expanding turning vanes in "C-Corner", and into the face of the heat exchanger. There, the air gets chilled/warmed within a controllable temperature range of $+20 \mathrm{C}$ total to -40C static. Twenty-four RTDs distributed on the D-Corner contracting turning vanes record the total temperature in this D-Corner plenum area. With good eyes, they can be seen from the inset picture. The tunnel height at the heat exchanger is 26.2-ft.

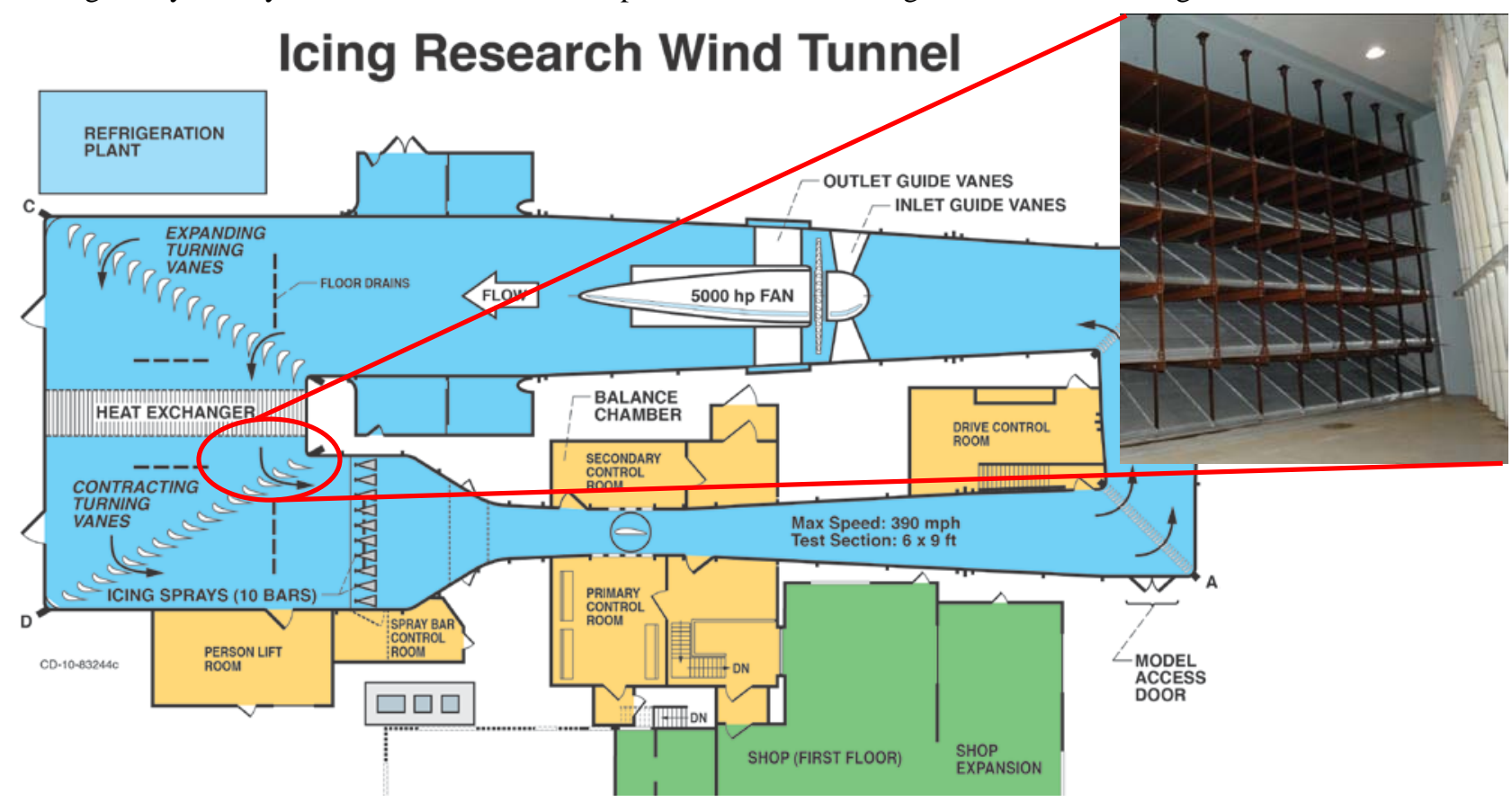

Figure 2. A plan view schematic of the 2012 Icing Research Tunnel. Inset: View of the new heat exchanger and inner D-Corner turning vanes (flow is left to right).

Downstream of the D-Corner turning vanes are 10 rows of spray bars with two different air-atomizing nozzle types: Mod1 (lower water flow rates) and Standard (higher water flow rates). Each bar has 55 positions that contain either a Mod1 nozzle, a Standard nozzle or a plug. These issue the icing cloud. It is possible to turn on only the Mod1 nozzles, only the Standard nozzles or both (with the same air pressure). The struts mounted vertically between spraybars that were required to help mix the cloud in 2006 are still required ${ }^{5}$.

The contraction area ratio into the test section is 14:1. The test section itself is $20 \mathrm{ft}$ long (axial) by 6-ft high by 9-ft wide. From the test section, the cloud flows into the diffuser toward A-Corner, and on around into B-Corner and into the fan. Any liquid moisture still present is deposited on the heat exchanger as long as the total temperature is $-10 \mathrm{C}$ or colder.

\section{Calibration Procedure and Results}

The full calibration procedure and results are described below for each of the steps in the process: cloud uniformity, drop size measurements (reported in MVD) and liquid water content, LWC.

\section{A. Cloud Uniformity}

Before the cloud characteristics of MVD and LWC can be determined, a uniform cloud has to be established. This is determined by identifying which of the 550 possible nozzle locations should spray Mod1, which should spray Standard nozzles, and which should be plugged. 
The diagnostic device is a $6 \times 6 \mathrm{ft}$ grid. This grid extends floor to ceiling, and covers the central 6-ft of the 9-ft span. The grid mesh is $6 \times 6$ in. Mesh elements are 2-inches deep with a flat 1/8-inch face for ice accretion. Digital calipers are used to obtain the ice thickness accreted at the center mesh point of the vertical elements. An image of a technician measureing ice on the grid is shown in Figure 3.

The first step in developing a uniform cloud is to establish a nozzle transfer map. Single rows and columns issue spray to see where they impinge supercooled liquid water on the grid. This transfer map both aids in the optimization of nozzle locations to produce a uniform cloud, and to locate problematic

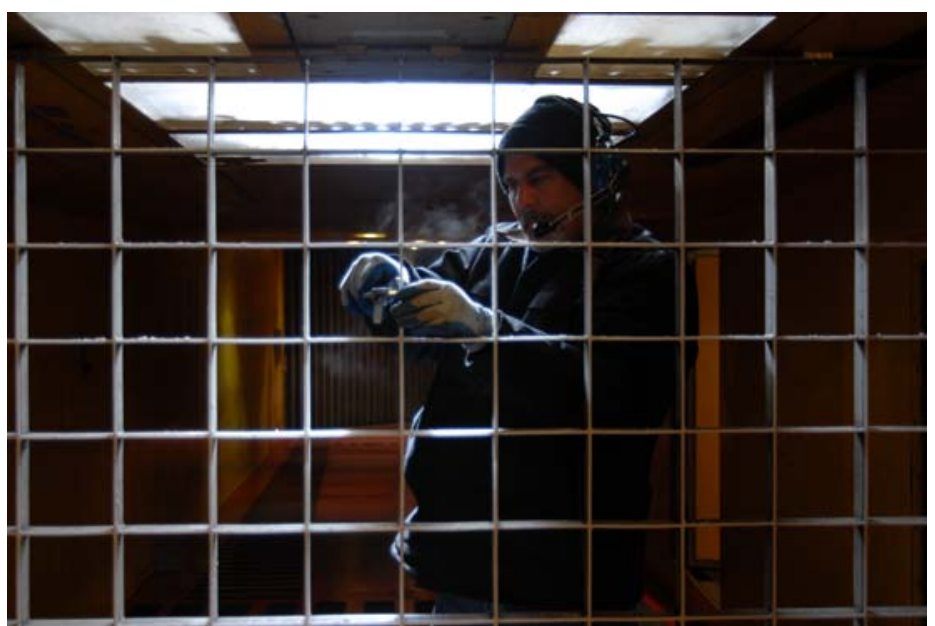

Figure 3. Cloud Uniformity: measuring ice thickness on the grid. nozzles subsequently.

An open question was whether or not the additional struts added between spraybars in 2006 were still needed (details described in Ide ${ }^{5}$ ). From the computational results of Clark ${ }^{4}$, the Cal Team expected to see much greater turbulence mixing with the struts than without, and to expect better mixing at the inner wall (North side) than outer wall. We in fact saw this with the grid. Without the struts, individual nozzle locations were identified by local maxima on the grid, whereas with the struts, the cloud was much more uniform. Furthermore, there was much more spread in the cloud from individual columns toward the inner wall than outer wall columns.

Armed with this knowledge, the Cal Team decided to start with a minimalist pattern, every $4^{\text {th }}$ nozzle position for the Mod-1 nozzles, to see how much the overall LWC could be lowered toward the FAR 25 Appendix $C^{6}$ requirement. The plan worked, the IRT gained a more uniform cloud spraying only 75 Mod1 nozzles compared to 90 nozzles in 2009. The Cal Team also chose to keep the Standard nozzle pattern at nominally the same number, so as not to lose the upper LWC end of Appendix C.

Since the majority of the IRT's models are airfoils mounted vertically and centered in the test section, greater care was taken to make the center 12 to 18-in width as uniform as possible. The Mod-1 cloud uniformity for the baseline condition of $150 \mathrm{kts}, 20 \mathrm{um}$ is shown in Figure 4 along with the corresponding condition from the previous full calibration in 2009. They indicate the Mod1 uniformity has improved with the new heat exchanger. As before, the Standard nozzle uniformity for this baseline case (not shown) is essentially monochromatic: LWCs are within $\pm 10 \%$ over most of the grid.

\section{B. Droplet Sizing}

Three instruments are required to cover the full range of accretable drop sizes generated in the IRT: 5 - 1300 um. Historically, these were the FSSP (2 - 47 um), OAP-230X (15 - 450 um) and OAP-230Y (50 - 1500 um), all made by the now defunct Particle Measurement Systems, Inc. In 2008, the IRT purchased modern equivalents of these legacy probes: the CDP (2 - $50 \mathrm{um})$, CIP (15 - $930 \mathrm{um})$ and PIP (100 - $6200 \mathrm{um})$, all made by Droplet Measurement Technologies, Inc (Boulder, CO). The Cal Team has recently tested the three DMT instruments as well as a PDI made by Artium, Inc. (Sunnyvale, CA) in the IRT.

In preparation for this calibration cycle, the legacy FSSP was sent out for maintenance and a replacement of its 12yr old multi-mode He-Ne laser. The laser that was returned had a sample area $71 \%$ larger than the previous laser. This change rendered the FSSP unusable in the IRT. Its high number densities violated the "single particle in the measurement volume" assumption. This was detected by seeing higher MVDs and lower number densities compared to the previous calibrations. A replacement laser guaranteed to have a smaller sample area was not easily found. Therefore, we installed the FSSP follow-on, a CDP. Unfortunately, the model purchased had an extreme baseline drift on the qualifier diode electronics, and was not usable in the time-frame of the calibration window. However, 
the problem has been fixed, and the CDP probe returned in time for the Summer calibration scheduled for June 4 - 8, 2012. These results will not be reported here.

A full data set for both nozzles was taken with the OAP-230X probe. The results from this December 2011 entry show nominally the same distributions compared to the previous April 2009 drop size calibration. That is, neither the new heat exchanger nor the decrease in number of Mod1 nozzles substantially affected the distributions in the $15-450$ um range. The Cal Team was not surprised by this. An example from one case is shown in Figure 5. Note that the first three bins of the OAP230X overlap with the FSSP; these three OAP bins are not used in the dropsize calculation, so differences here do not factor into the MVD calculation. The Cal Team determined that the interim solution was to continue with the 2009 drop size calibration until a valid, full-range calibration could be achieved.

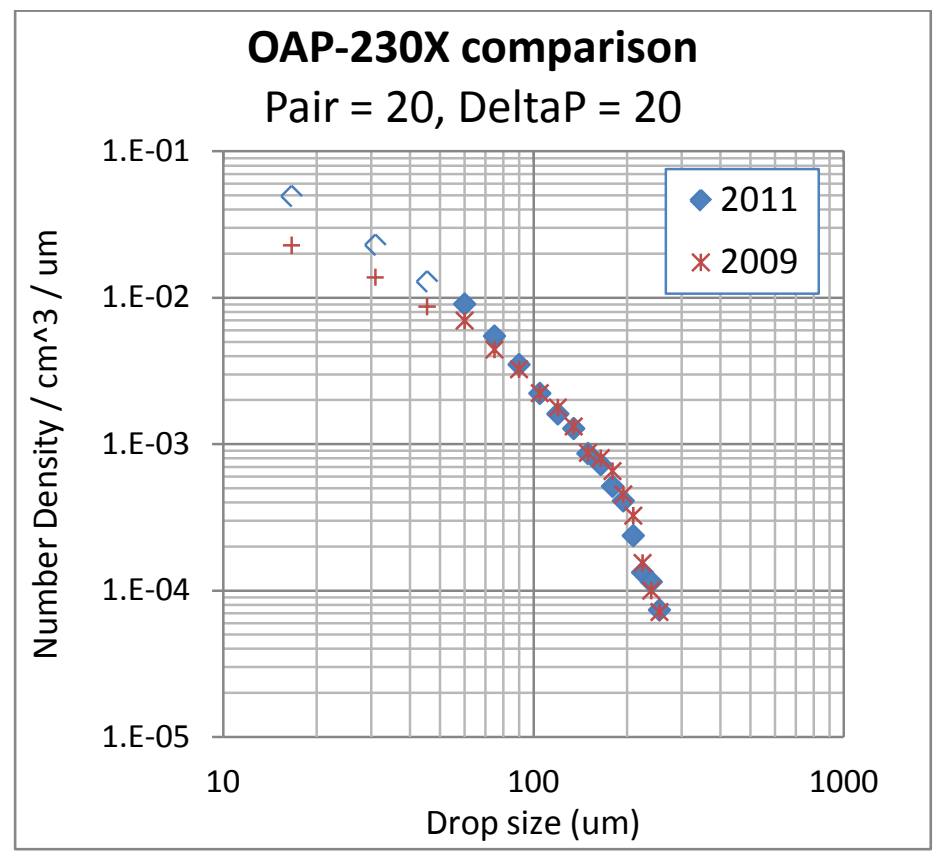

Figure 5. Comparison of OAP-230X number densities measured for a case in 2009 and 2011. Note: the smallest three bins are not used the MVD calculation.

It should be noted that the IRT has always produced large drops. Figure 6 shows a comparison of IRT distributions (from 2009) to the four FAA Appendix O conditions for supercooled large droplets, SLD ${ }^{7}$ : freezing drizzle (FZDZ), MVD $<40$ um, FZDZ, MVD $>40$ um, freezing rain (FZRA), MVD $<40$ um and FZRA, MVD $>40$ um.

When comparing distributions to the FAA standards, it is important to know which characteristics are important to match. Perhaps MVD is preeminent (as it has been for Appendic C), or perhaps other points along the distribution. Perhaps the general bimodal shape is more important than specific waypoints. MVD, also known as Dv0.5, is the dropsize at which half the volume is contained in larger drops and half in smaller. Matching Dv0.9 means $90 \%$ of the cumulative volume (or mass) is contained in smaller drops. For an ice shape, $90 \%$ of the liquid volume contained in the drops would be accreted. Since Appendix O is concerned with the effect of large droplets, comparing Dv0.9 (or similar, e.g., Dv0.95 or Dv0.8) is one way to illuminate that. The points of Dv0.9, Dv0.5 and Dv0.1 are indicated in Figure 6. The bimodal characteristic, almost assuredly, requires two nozzle sets to replicate. The most important characteristics to match of the FAA Appendix $\mathrm{O}$ is is an important discussion. The authors are not aware that it has had any vetting within the icing community.

Regarding observations of the IRT distribution data for Appendix O: for FZDZ, MVD $<40$ um, the IRT matches the target Dv0.1 and Dv0.9 fairly well, but overshoots the Dv0.5 (=MVD) point. For the FZDZ, MVD $>40$ um target distribution, the IRT matches Dv0.5 and Dv0.9 well, but overshoots Dv0.1. For FZRA, MVD $<40$, the IRT can match either the large drop tail at Dv0.9 (presumed to be more important) or the smaller drop size elements at Dv0.1 and Dv0.5. For FZRA, MVD $>40$ um, there is poor in between both the shape of the target distribution and target volume comparison point. A few things to consider in tunnel generated drops includes supercooling of the drop. Even with the IRT's 44-ft distance from the spray bars to the center of the test section and 14:1 contration ratio effect on dropping static temperaure, there is evidence that the drops greater than 60 um have not fully supercooled to the air temperature. Another consideration with horizontal wind tunnels is the "sink" rate of very large droplets. The authors anticipate that the IRT will never produce acceptable FZRA, MVD > 40 um conditions 


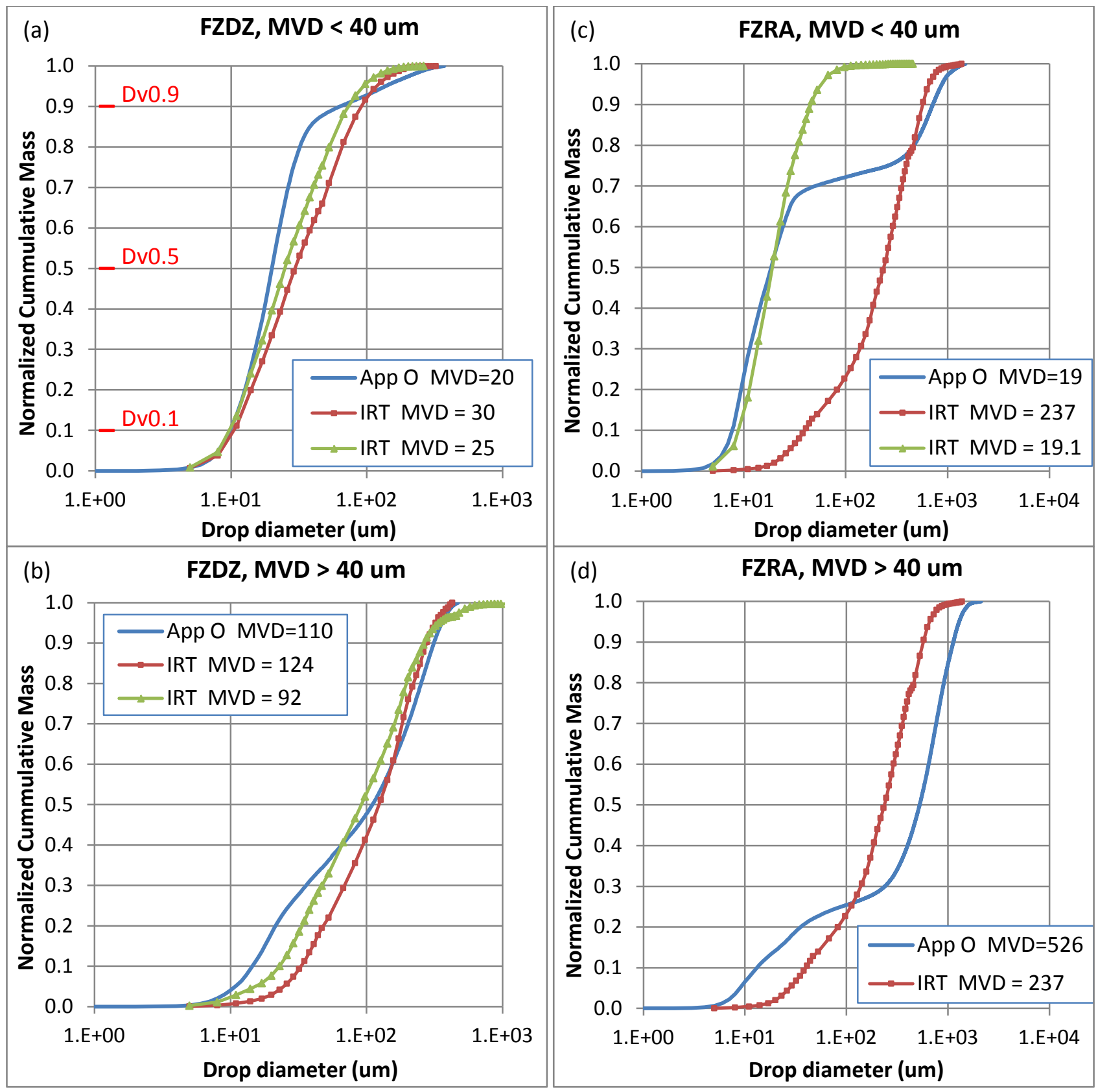

Figure 6. Comparison of cummulative mass distributions between the FAA Appendix $O$ and corresponding IRT distributions (2009) for (a) Freezing Drizzle (FZDZ) with MVD $<40$ um, this graph also depicts the Dv0.5 and Dv0.9 locations; (b) FZDZ with MVD > 40 um; (c) Freezing Rain (FZRA) with MVD < 40 um, and (d) FZRA with MVD > 40 um.

\section{Liquid Water Content}

Historically, an Icing Blade has been used for the liquid water content (LWC) calibration in the IRT. Rime ice accretes on the Blade, which is rectangular prism with the forward facing dimension of 0.125-in and a depth of 0.75in. (see Fig 7a). The ice thickmess measurements are taken with digital calipers at three different heights: center, center \pm 1 -in. The median value is used to calculate $L W C$ and a parameter ' $K$ ' via the following equations: 


$$
\begin{gathered}
\mathrm{LWC}=43440 * \delta /(\mathrm{Eb} * \mathrm{~V} * \mathrm{t}) \\
\mathrm{LWC}=\mathrm{K}(\mathrm{V}, \text { Pair }) * \mathrm{~V} *(\text { DeltaP })^{-1 / 2}
\end{gathered}
$$

where $\delta$ = ice thickness (in), Eb = collection efficiency of the Blade, $\mathrm{V}=$ airspeed (knots), $\mathrm{t}=$ spray time (sec); the 43440 value includes unit conversion coefficients and an ice density value of $0.88 \mathrm{~g} / \mathrm{m}^{3}$. The collection efficiency is a function of airspeed, drop size and model geometry. For this design, Eb was calculated by the FWG twodimensional droplet trajectory code ${ }^{8}$ using a Hess-Smith panel code for the flowfield prediction and a C. W. Gear stiff equation scheme to integrate particle trajectories. The parameter $\mathrm{K}$ has been determined to be a function of airspeed and atomizing air pressure. Determining the nature of these functions is the key to the LWC curve fit.

The Blade works well as long as the assumptions are valid: droplets freeze on impact so there is no mass loss, and the accreted ice shape does not have a significantly different Eb. To support these assumptions, the total air temperature is kept between -18 C to -20 C (easily a hard rime for lower LWCs). Spray times are also such that the target ice thickness is 0.1 to 0.2 -in thick. The blade response starts to roll off for both high LWC conditions (mixed/glaze ice instead of rime and/or extremely short spray times), and large droplets (due to splashing). Experience in the IRT suggests the Blade responds well for $\mathrm{LWC}<1.5 \mathrm{~g} / \mathrm{m}^{3}$ (not a hard limit), MVD $<60 \mathrm{um}$, and $50 \leq \mathrm{V} \leq 200 \mathrm{kts}$. Some Standard nozzle sprays are on the order of 12 -sec for mid DeltaPs. LWCs for larger DeltaPs are not calibrated but extrapolated.

For better or for worse, the Blade's limitations came into play during this calibration. At the same time the refrigeration plant and heat exchanger were being upgraded, so was Ovation ${ }^{\circledR}$, the facility control software. During the first few LWC calibration runs, two issues with the new Ovation upgrade were discovered and ultimately corrected: one was that sprays were lasting 2-sec longer than commanded; the other was that the spraybar 'spray on' command had not yet been tuned to prevent significant DeltaP pressure transients. These could be quite large and long-lived at the spray on

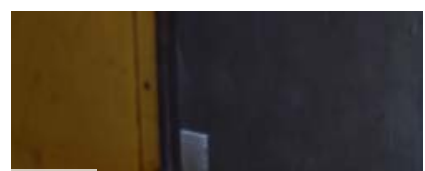

(a)
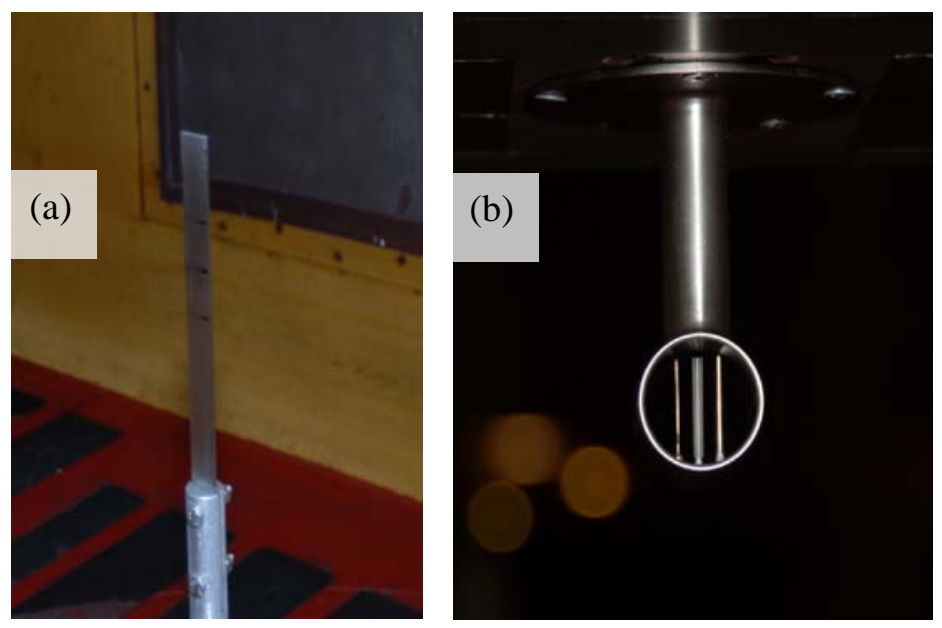

Figure 7. Liquid water content instruments: (a) Icing Blade and (b) Multi-wire with the 2-mm half-pipe in the center.

command. Both of these issues have now been corrected, but the limiting assumptions of the Blade rendered it unusable during this particular calibration sequence.

The Cal Team decided it was prudent to shift to Science Engineering Associates's (SEA; Mansfield Hollow, CT) Multi-wire instrument, shown in Figure 7b. The Multi-wire has four heated elements that are held at a constant 140 C. The current required to maintain this temperature is proportional to the amout of water it must evaporate. This particular sensor, SN 2022, has a 2-mm half-pipe in the center that measures both liquid and ice, or Total Water Content, TWC. It is flanked by a 2-mm hollow tube and a $0.5-\mathrm{mm}$ wire; these respond primarily to liquid. The fourth "compensation" wire is designed to stay dry so that it tracks temperature and airspeed effects only. As with the Blade, a collection efficiency for each element was determined and applied.

The Cal Team had previous experience with the Multi-wire via several entries prior to this calibration, and found it to be very satisfactory. As seen in Figure 8, the Blade and Multi-wire TWC have good agreement where good agreement is expected. Where the Blade is expected to be less responsive, i.e., at high LWC and large drops (upper right point in Fig 8b), the Multi-wire TWC recorded a much higher value. An independent check of the accumulation parameter on an ice shape supported the Multi-wire value of 4.0 vs the Blade's $2.2 \mathrm{~g} / \mathrm{m}^{3}$. The Multiwire also has the advantage of being spray time independent, temperature independent (over the range tested), and 


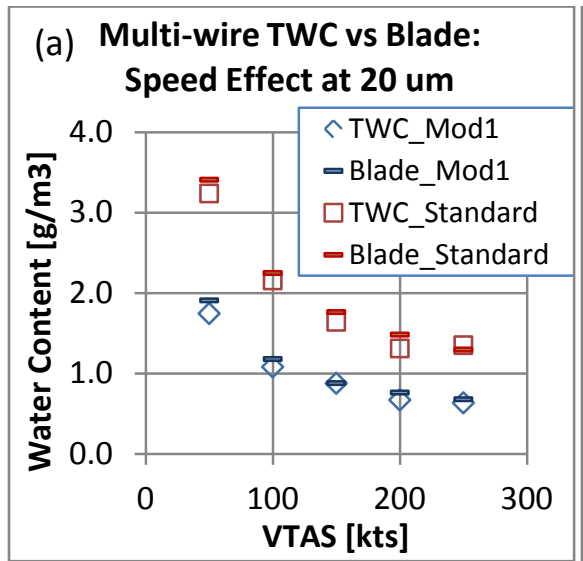

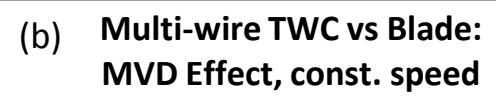

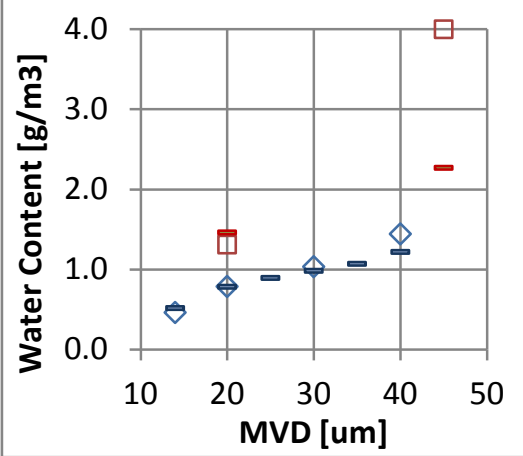

Multi-wire vs. Blade: SLD Conditions

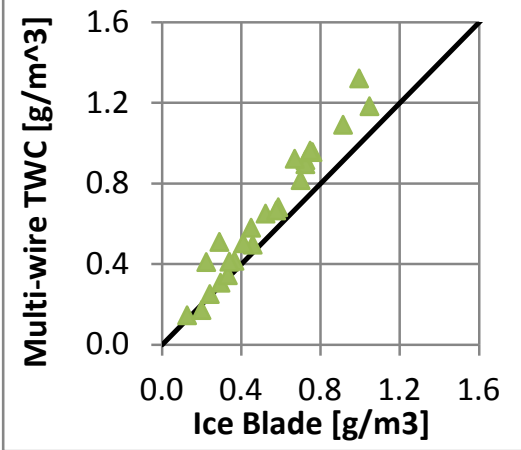

Figure 8. Comparison of LWC measurements between the Blade and the Multi-wire TWC: (a) LWC measurement vs airspeed at $20 \mathrm{um}$, (b) LWC vs MVD at 150 kts (Mod1) or 200 kts (Standard). Same legend for both (a) and (b) graphs; (c) head-to-head comparison for SLD Conditions (Pair < 10 psig) with the 1:1 line shown for reference.

not rolling off in response at the higher air speeds or higher LWCs tested in the IRT. It is also responsive to the presence of ice crystals.

\section{Ice Crystals}

The Cal Team capitalized on the Multi-wire's capability to detect ice crystals. It was instrumental in determining whether or not the ice particle shed off the heat exchanger was, in fact, resolved.

Several tests were conducted with the Multi-wire to illuminate ice shedding events. The first task was a "dry" one. The heat exchanger was coated with frost, then the airspeed increased to 'scrub' the heat exchanger without turning spray on. From both the Multi-wire and visual observations of at D-Corner from the control room, some shedding was seen as the speed ramp exceeded 250 kts. Fortunately, after $3-5$ minutes the ice particles dissipated; the visual still corresponding with the measurement.

The other tasks were with spray. Shown in Figure 9, is a condition at a very cold static temperature, -41C (where one might not necessarily expect liquid water), $250 \mathrm{kts}$ and $20 \mathrm{um}$ (Pair $=40 \mathrm{psig}$, DeltaP $=160 \mathrm{psid}$ ). One sees the half-pipe responding to the total water content, whereas the cylindrical sensors reply primarily only to liquid water. The large discrepancy in Water Content values, $0.35 \mathrm{vs} 0.1 \mathrm{~g} / \mathrm{m}^{3}$, indicates the presence of ice crystals ${ }^{9}$. The precipitous drop in TWC around 18:10:36 marks the spray off, but the long "tail" indicates recirculating ice crystals (vs ones shed from the heat exchanger). This is perhaps also seen in the slight increase in TWC trend during the spray. In this case, just over one minute is required for the measurable effect to dissipate.

The new refrigeration system is capable of driving to much colder temperatures, about -43C static, than the previous system. Limited testing was conducted at these very cold temperatures. While maintaining 150 kts and 20 um (spray conditions: Pair $=40$ psig, DeltaP $=160$ psid), the Cal Team drove the tunnel air temperature toward the coldest temperatures possible. Figure 10 shows that for

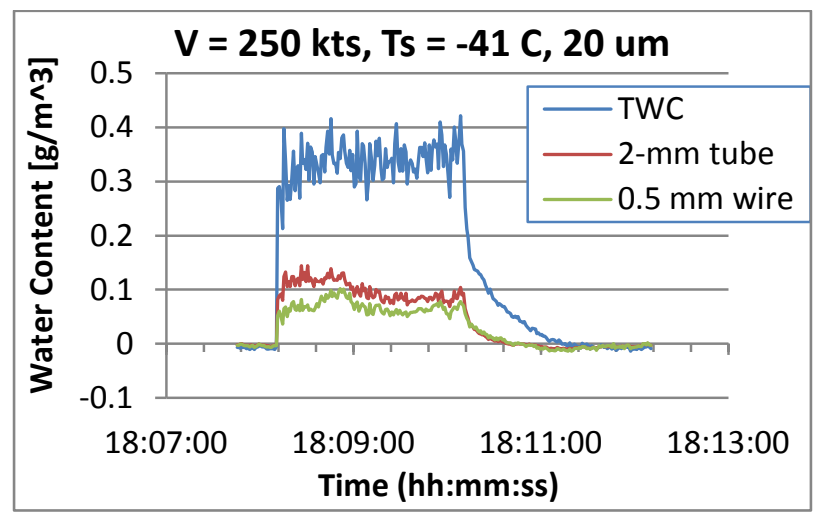

Figure 9. Example of ice crystal recirculation with spray on.

8

American Institute of Aeronautics and Astronautics 
static temperatures above -36C, all three multi-wire elements responded in their characteristic fashion to supercooled liquid water. Driving toward -38C, the wires started to fall-off while the TWC sensor remained constant; this is indicative of mixed phase with ice crystals ${ }^{9}$. Below a static temperature of -40 there was a significant decrease on all sensors. As it turns out for this run, some of the nozzles had frozen shut. IRT personnel are making efforts to better insulate the spray bars so that the IRT might be able to produce a calibrated mixed phase or ice crystal cloud.

The ice crystal testing conducted thus far demonstrates a significant reduction in ice crystals. However, it also shows a need to improve the understanding of IRT operations at static temperatures below -35C. Possibly, the IRT will be able to generate a calibrated mixed phase or ice crystal cloud.

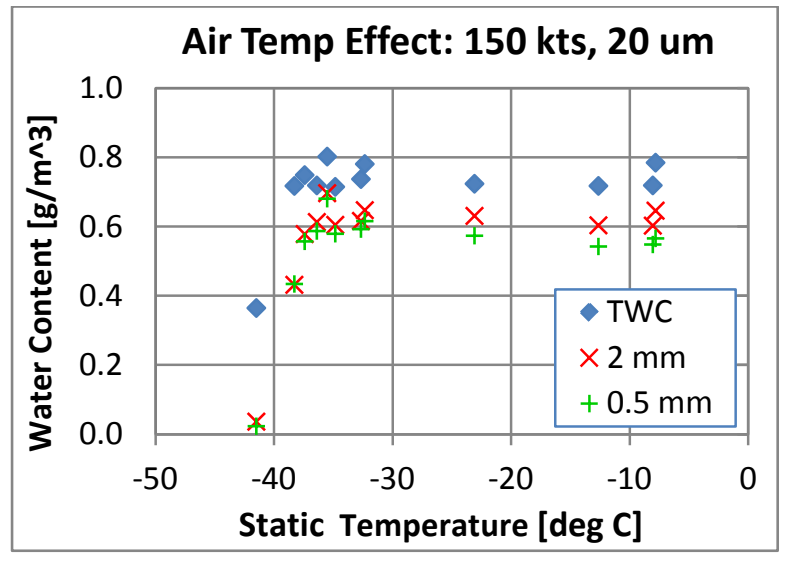

Figure 10. Static Air Temperature effect on liquid droplets vs. ice crystal production.

\section{Calibration Curve Fits}

The results of the MVD and LWC calibration efforts is next pulled together to create a calibration surface to map (Pair, DeltaP) to (MVD, LWC) at different airspeeds.

\section{A. MVD Curve Fits}

The MVD curve fit equations were determined by inputing the measured Pair, DeltaP and MVD into the curve fit generator TableCurve ${ }^{\circledR}$. While fairly complex equations, they clearly fit the data well.

The Mod1 MVD curve fit equation is

$$
\begin{gathered}
M V D_{\text {Mod } 1}=a+b * z 1+e * z 2+h * z 1 * z 2 \\
\ln (z 1)=-0.5 *((\ln (\text { Pair } / c) / d) *(\ln (\text { Pair } / c) / d) \\
\ln (z 2)=-0.5 *((\text { DeltaP }-f) / g) *(\text { DeltaP }-f) / g
\end{gathered}
$$

Where $\mathrm{a}=8.758, \mathrm{~b}=-75.21, \mathrm{c}=6.345, \mathrm{~d}=0.7341, \mathrm{e}=15.066, \mathrm{f}=557.3, \mathrm{~g}=265.2, \mathrm{~h}=679.5$.

The Standard MVD curve fit equation is,

$$
\begin{gathered}
M V D_{\text {Standard }}=a+b * z 1+e * z 2+h * z 1 * z 2 \\
\ln (z 1)=-0.5 *((\ln (\text { Pair } / c) / d) *(\ln (\text { Pair } / c) / d) \\
\ln (z 2)=-0.5 *((\text { DeltaP } / f) / g) *(\text { DeltaP } / f) / g
\end{gathered}
$$

Where $\mathrm{a}=14.75, \mathrm{~b}=7.116, \mathrm{c}=3.738, \mathrm{~d}=0.8174, \mathrm{e}=72.65, \mathrm{f}=1773.8, \mathrm{~g}=1.434, \mathrm{~h}=19314.5$.

Figure 11 summarizes the MVD curve fits. In 11a and 11c, the measured MVDs from Mod1 and Standard nozzles respectively, are plotted against the curve fit for two Pair lines. In 11b and 11d are the MVD 'goodness of fit' plots 

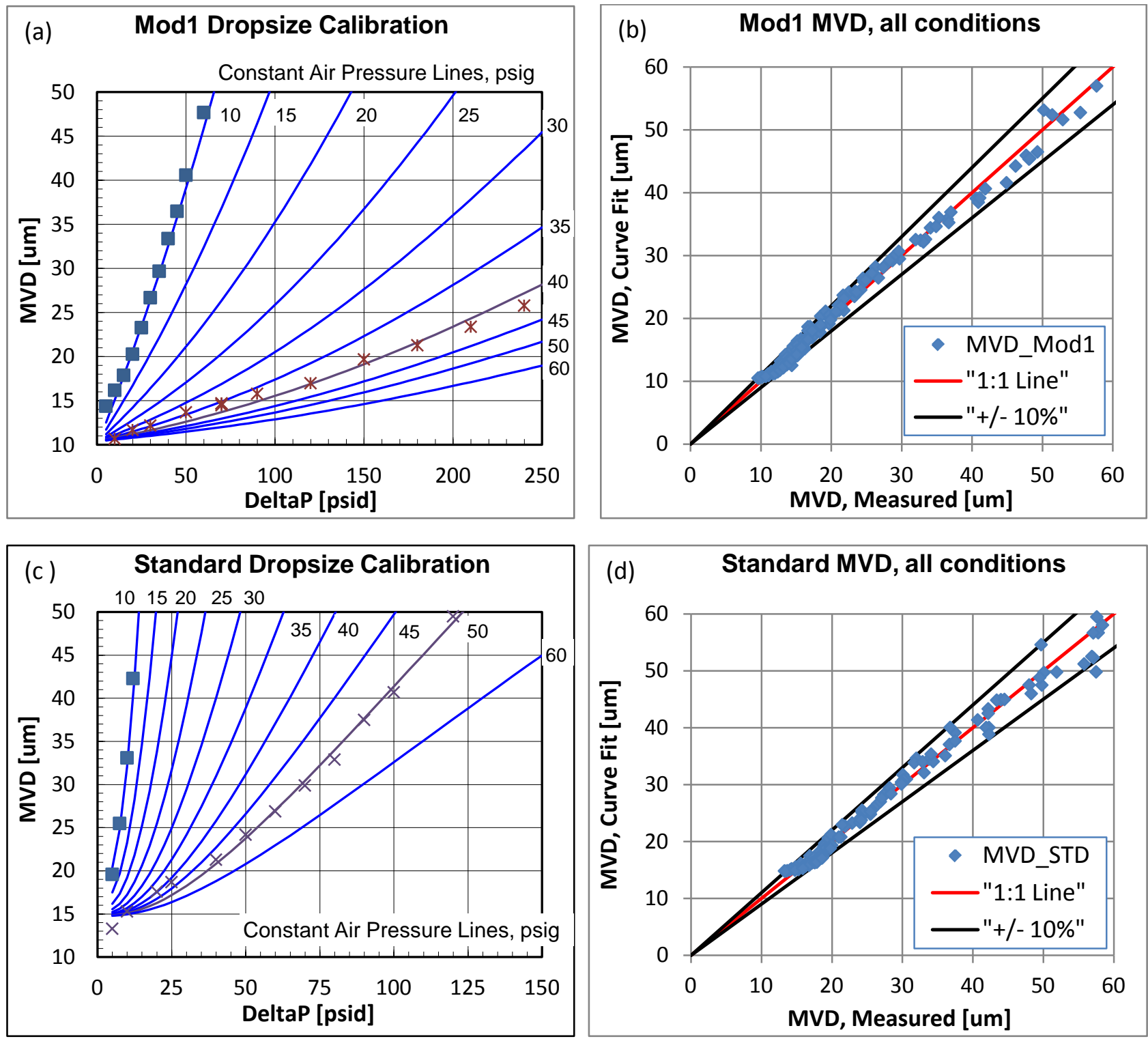

Figure 11. Curve fit of Drop size data (from 2009). (a) Mod1 curve fit lines for each air pressure line with increasing DeltaP. Measured MVD points for Pair = 10 and 40 psig are also shown. (b) Summary of all the Mod1 measured data compared to the curve fit. (c) Standard curve fit lines for each air pressure line with increasing DeltaP. Measured MVD points for Pair = 10 and 50 psig also shown. (d) Summary of all the Standard measured data compared to the curve fit.

for all Mod1 and Standard conditions, respectively. The 1:1 line, as well as $\pm 10 \%$ lines are shown for reference. One can see from all plots that the data match very well.

\section{B. LWC Curve Fits}

With the 2012 LWC calibration, the 'K' parameter has a new element, MVD, for both the Mod1 and Standard nozzles. Perhaps this is due to the better response of the Multi-wire. This drop size effect became apparent while attempting to construct the curve fits. Unfortunately, the addition of this factor complicates the iteration scheme in the Spraybar Calculator. 

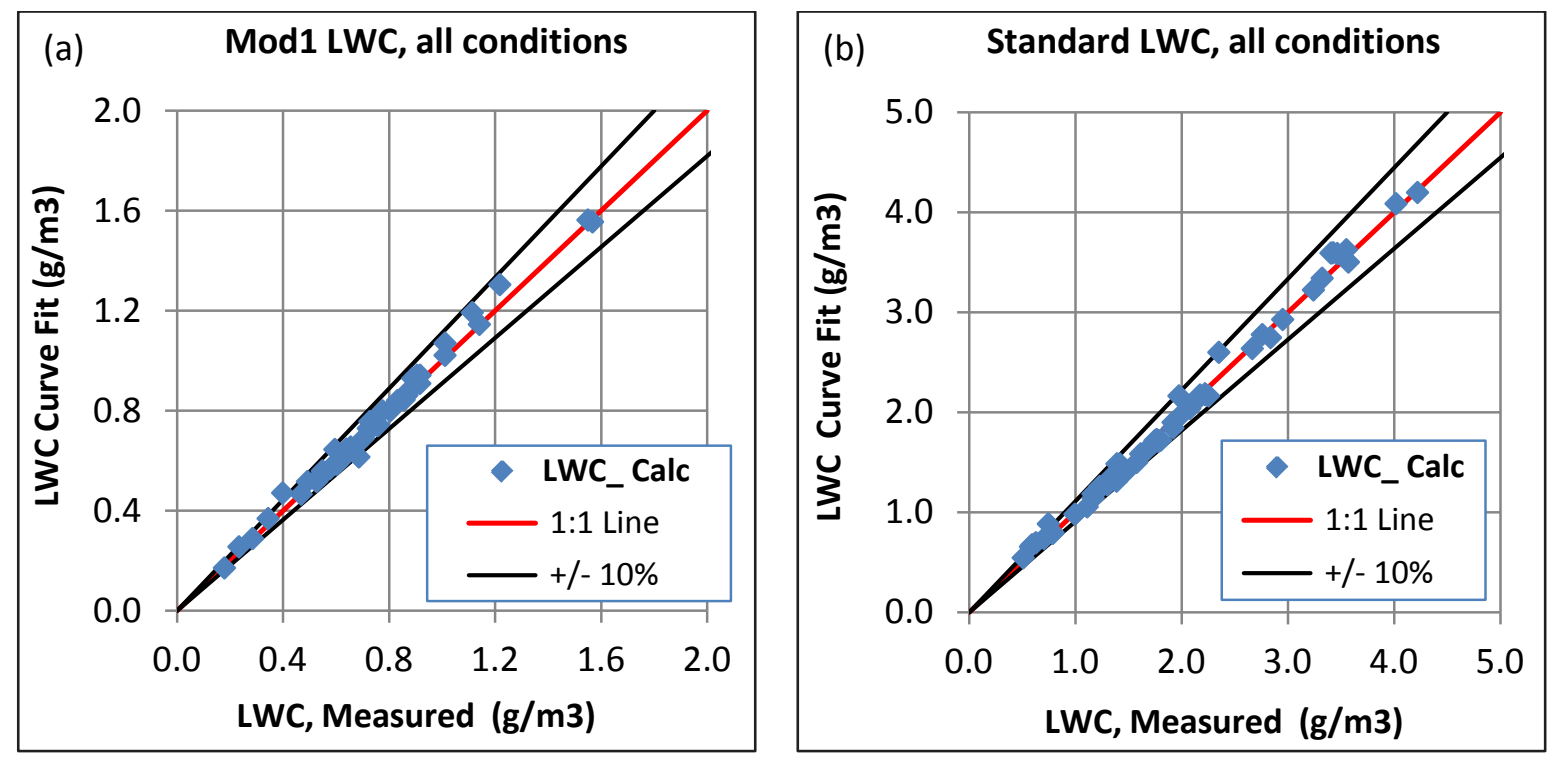

Figure 12. Curve fit of LWC data. (a) Summary of all the Mod1 measured LWC data compared to the curve fit. (b) Summary of all the Standard measured LWC data compared to the curve fit.

The Mod1 LWC curve fit equation is

$$
L W C_{M o d 1}=(a * V+b * \text { Pair }+c) *(M V D / 20)^{\wedge} d * \operatorname{sqrt}(\text { DeltaP }) /(V)
$$

Where $\mathrm{a}=0.027268, \mathrm{~b}=-0.02909, \mathrm{c}=5.8469, \mathrm{~d}=0.176$.

Similarly, for the Standard LWC curve fit,

$$
L W C_{\text {Standard }}=(a * V+b * \text { Pair }+c) *(M V D / 22)^{\wedge} d * \operatorname{sqrt}(\text { DeltaP }) /(V)
$$

Where $\mathrm{a}=0.1539, \mathrm{~b}=-0.126, \mathrm{c}=32, \mathrm{~d}=0.2$. The curve fit results are shown in Figure 12 .

The IRT's icing envelopes for both the Mod1 and Standard nozzles is compared to Appendix C in Figure 13 . The airspeed of $200 \mathrm{kts}$ is selected. At lower air speeds, the curves would shift up slightly to higher LWC, at higher air speeds, they shift down slightly in LWC. Note that a commonly requested data point, MVD = 40 um, LWC $=0.1$ $\mathrm{g} / \mathrm{m}^{3}$ will likely never be achieved in with the current nozzles.

The effect of reducing the total number of Mod1 nozzles by 19\% in 2012 lead to a corresponding reduction in LWC between $12 \%$ to $22 \%$, depending on the specific condition.

\section{SLD Curve Fit Results}

For the discussion in this section only, "SLD” refers to the Mod1 nozzles spraying at low atomizing air pressures, Pair $\leq 8$ psig. Low atomizing air pressures do not break up the liquid jet as effectively, so larger drops are expected. As mentioned in Section IV. B., even within the typical operating range of $10 \leq$ Pair $\leq 60$ psig, the IRT nozzles produce distributions with fairly long tails, i.e., large drops, that could satisfy the new Appendix O requirements.

The drop size data was easily curve-fit back in 2009, but the LWC, then measured by the Blade, suffered from rolloff, especially at higher air speeds. It was impossible to generate a curve fit valid for the four airspeeds tested. With the multi-wire, however, the LWC trends are clear, consistent, and lend themselves to a fit. 


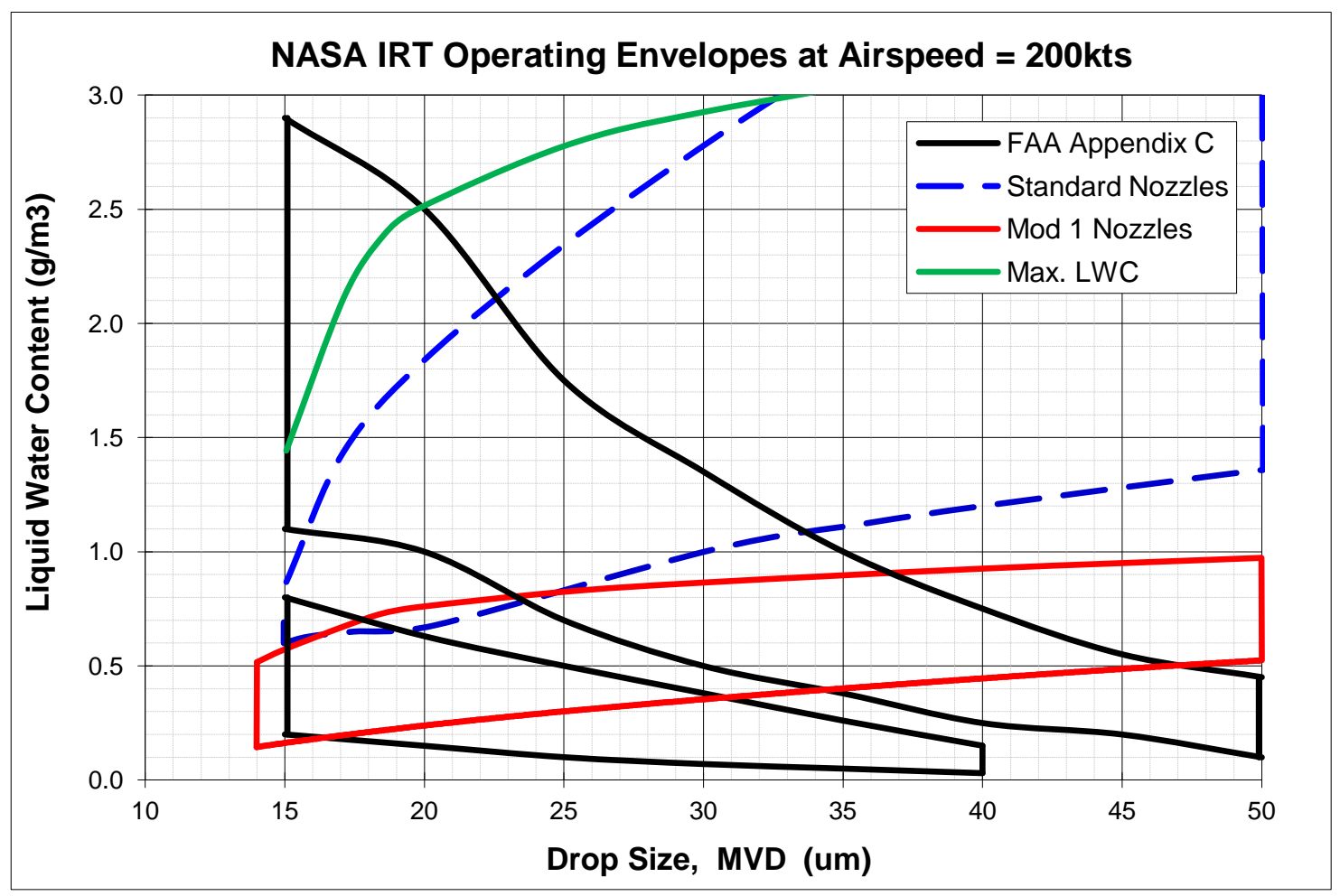

Figure 13. IRT Icing Envelop at 200 kts. The FAA Appendix $C$ envelopes are indicated in black. The Mod1 nozzles in red and the Standard nozzles in dashed blue. The Mod1 and Standard nozzles can be combined under limited circumstances to produce higher LWC, shown in green.

The MVD curve fit for Mod1 nozzles, Pair < 10 psig is,

$$
M V D_{S L D}=\operatorname{EXP}\left[a+b * \sqrt{\text { Pair }}+c * \ln (\text { Pair })+\frac{d}{\sqrt{\text { Pair }}}+\frac{e}{\text { Pair }}+f * \frac{\ln (\text { Pair })}{\text { Pair }^{2}}+g * \ln (\text { DeltaP })^{2}\right.
$$

Where $\mathrm{a}=-2126.2, \mathrm{~b}=-227.6, \mathrm{c}=792.9, \mathrm{~d}=3645.2, \mathrm{e}=-1254.0, \mathrm{f}=-279.2, \mathrm{~g}=0.1516$.

The corresponding LWC curve fit is

$$
L W C_{S L D}=(a * V+b * \text { Pair }+c) *(M V D / e)^{\wedge} d * \operatorname{sqrt}(\text { DeltaP }) /(V)
$$

Where $\mathrm{a}=0.003 .2, \mathrm{~b}=-0.187, \mathrm{c}=13.0, \mathrm{~d}=0.22, \mathrm{e}=41$. These SLD curve fit results are shown in Figure 14 .

\section{Conclusion}

Reported herein are the procedures and results of the full cloud calibration that took place in NASA Glenn's Icing Research Tunnel following replacement of the original 1940's refrigeration plant and 1999 flat panel heat exchanger. The effort began early November 2011 and was completd at the end of January 2012.

The new staggered heat exchanger design lent itself to improved cloud mixing. Both uniformity surface plot maps and customer comments indicate how much improved the uniformity is over the previous full calibration in April 2009. Because of the enhanced cloud mixing, the Cal Team was able to reduce the total number of Mod1 nozzles by $20 \%$, which dropped the overall LWC by a range of $12 \%$ to $22 \%$. Thus, the IRT's lowest LWC was successfully driven lower, toward the lower end of the FAA Appendix C icing certification requirement. At the same time, the Cal Team kept the number of Standard nozzles constant; not substantially changing the upper LWC limits. This did open up a small gap between nozzle sets. 

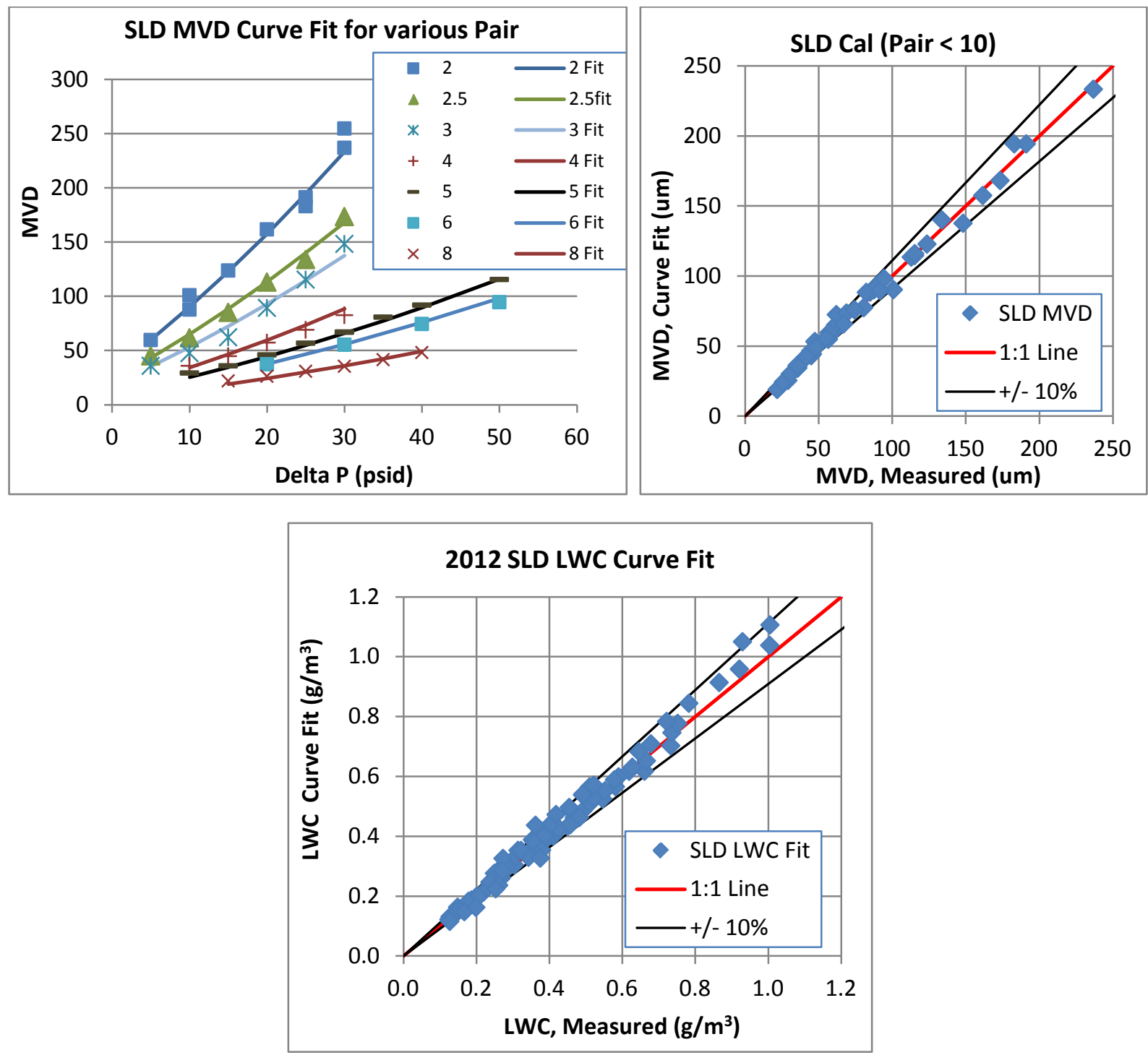

Figure 14. SLD (Pair < 10 psig) Curve fits. (a) Measured MVD plotted on curve fit MVD for each calibrated Pair line. (b) Summary of MVD goodness of fit. (c) Summary of LWC goodness of fit.

This calibration also marks the first official use of the IRT's new LWC sensor standard. The Icing Blade was replaced with a heated wire system, SEA's Multi-wire. With this more responsive wire, we were able to extend the calibration into higher LWCs and larger MVDs. While instrumentation issues prevented a successful full drop size calibration, the mid-range sizer OAP-230X indicated no substantial changes in the drop size calibration from 2009. Therefore, these calibration curves will remain in effect until such time as a full calibration can be obtained.

\section{Acknowledgments}

The Authors, aka the Cal Team, would like to thank NASA's Aeronautics Test Program for funding this essential effort, the IRT Facility Manager (and former Cal Team member) Jack Oldenburg; the skilled IRT Engineers: Dave Sheldon, Seth Sederholm, Larry Becks and Mark Kubiak; and the expert IRT Technicians: Joe August, Paul Butterfield, Dave Justavick, Jim Knight, Ed LaMarche, Bill Magas, Terry Mathes, Shaun McNea, Pat Murphy, 
Perry Vraja. This intense effort required support and willingness to go the extra mile from each of these. Also thanks to Colin Bidwell, Mr. LEWICE3D for running the collection efficiencies on the multi-wire elements.

It should also be noted that NASA does not necessarily endorse any of the brand names listed herein.

\section{References}

${ }^{1}$ SAE ARP-5905, “Calibration and Acceptance of Icing Wind Tunnels”, Society of Automotive Engineers.

${ }^{2}$ Pastor-Barsi, Christie. M., Arrington, E. Allen., "2012 Aero-Thermal Calibration of the NASA Glenn Icing Research Tunnel," $4^{\text {th }}$ AIAA Atmospheric and Space Environments Conference (submitted for publication), New Orleans, Jun 2012.

${ }^{3}$ Steen, Laura. E., Van Zante, Judith. F., Broeren, Andy. P., Kubiak, Mark. J., "NASA Glenn Icing Research Tunnel: Flow Quality Surveys in the Settling Chamber of the NASA Glenn Icing Research Tunnel (2011 Tests)," $4^{\text {th }}$ AIAA Atmospheric and Space Environments Conference (submitted for publication), New Orleans, Jun 2012.

${ }^{4}$ Clark, Kevin., Malinowski, Michael., Loth, Eric., Steen, Laura. E., Van Zante, Judith. F., Ide, Robert. F., “Air Flow and Liquid Water Concentration Simulations of the 2012 NASA Glenn Icing Research Tunnel," $4^{\text {th }}$ AIAA Atmospheric and Space Environments Conference (submitted for publication), New Orleans, Jun 2012.

${ }^{5}$ Ide, Robert. F., Sheldon, David W., "2006 Icing Cloud Calibration of the NASA Glenn Icing Research Tunnel”, NASA/TM-2008-215177, May 2008.

${ }^{6}$ FAA FAR 14 CFR 25, Appendix C, “Icing Certification”

${ }^{7}$ FAA FAR 14 CFR Parts 25 and 33, “Airplane and Engine Certification Requirements in Supercooled Large Drop, Mixed Phase, and Ice Crystal Icing Conditions”, Federal Register / Vol. 75, No. 124 /Tuesday, June 29, 2010 / Proposed Rules.

${ }^{8}$ Frost, W., “Two-Dimensional Particle Trajectory Computer Program,” Interim Report for Contract NAS322448, Mar. 1982.

${ }^{9}$ Van Zante, Judith. F., Ide Robert. F, Addy, H. Eugene., "PSL Technology Demonstration Testing”, to be published as a NASA TM. 